\title{
Febrile Seizures - Male Preponderance with Gradual Decline, Marked in Female with Age Advancement
}

\author{
Article by Mujahed Baig, Shujaat \\ Child Care Beed, India \\ E-mail: mujahed2600@gmail.com
}

\begin{abstract}
Objective: To know sex preponderance \& Recurrence incidence in case of febrile seizure.

Result: We observed male preponderance in case of febrile seizure \& gradual decline in case of male \& marked in case of female as age advances.

Conclusion: Febrile seizure had slightly more predilection for male sex, from such data and very short period of follow up, benign nature and continuous prophylaxis of disease can be explained to parents.
\end{abstract}

Keywords: benign nature, more predilection for male sex, continuous prophylaxis

\section{Introduction}

Convulsing child is one of the common emergency in pediatric OPD and it is a great Challenge to treating pediatrician to handle the situation with treatment of child and management of accompanying parents.

One of the commonest cause of seizure in Para infant age group is febrile seizure. Febrile seizures are described very well way back in fifth century BC by Hippocrates. Though he has mentioned generalized seizure as bad omen but has well described the benignness of febrile seizures in children of particular age group.

Convulsing child is great mental stress to accompanying parents so its very important to alleviate the anxiety and to tell them the exact nature and prognosis of the disease. Its very important for treating pediatrician to distinguish between the typical and atypical febrile seizures for explaining the prognosis to parents.

This study is small attempt to explore the true nature of the disease and its course. It is also an attempt to manage the disorder in rural set up with minimum investigational back up. It is conducted in a hospital, which has adopted villages for their health thus serving a large number of population.

\section{Methods}

This is a prospective clinical study of 96 cases of febrile seizure admitted for first febrile seizure during the period of August 2014 to January 2016 (18 months). They were followed up simultaneously during the same period on O.P.D Basis.

- $\quad$ Age group 3 months to 6 years.

- Fever with convulsions.

- No history of non febrile seizures in the past.

Definition of case: The patients were classified as a case of febrile seizure when following features were present

- Definite history and / or documentation of fever preceding seizure.

- No evidence of any intracranial infection or metabolic disorder of head injury causing convulsion.

- Routine CSF examination was within normal limits.

For study of intermittent $\mathrm{v} / \mathrm{s}$ continuous prophylaxis consent of parents were taken, those who were ready to participate were included, and those who rejected were excluded.

EEG was advised for cases having atypical febrile convulsion was ready by EEG specialist and was reported within a day. 
Texila International Journal of Clinical Research

Volume 4, Issue 1, Jun 2017

Results: The number of cases admitted during study period (Aug. 2014-Dec2015) in pediatric ward $=2200$

Number of cases of febrile seizure admitted during the same period $=69(4.36 \%)$

Table 1. Showing distribution of cases according to age

\begin{tabular}{|l|l|l|}
\hline $\begin{array}{l}\text { Age group } \\
\text { (Months) }\end{array}$ & No. of cases & Percentage (\%) \\
\hline$<6$ & 3 & 3.125 \\
\hline $6-12$ & 18 & 18.75 \\
\hline $12-24$ & 38 & 39.58 \\
\hline $24-36$ & 20 & 20.83 \\
\hline $36-48$ & 8 & 8.33 \\
\hline $48-60$ & 6 & 6.25 \\
\hline$>60$ & 2 & 2.83 \\
\hline Total & $\mathbf{9 6}$ & $\mathbf{1 0 0}$ \\
\hline
\end{tabular}

From the above table it is clear that maximum number of cases (79.16\%) were observed in age group of 6 months to 3 years.

Table 2. Showing distribution of cases according to sex

\begin{tabular}{|l|l|l|}
\hline Sex & No. & Percentage \\
\hline Male & 52 & 54.166 \\
\hline Female & 44 & 45.833 \\
\hline Total & $\mathbf{9 6}$ & $\mathbf{1 0 0}$ \\
\hline
\end{tabular}

Thus we observed male preponderance in cases of febrile seizure in the present series (M:F $-1.18: 1)$

Table 3. Showing distribution of cases in males according to age group

\begin{tabular}{|l|l|l|}
\hline $\begin{array}{l}\text { Age group } \\
\text { (Months) }\end{array}$ & No. of cases & Percentage (\%) \\
\hline$<6$ & 02 & 3.846 \\
\hline $6-12$ & 10 & 19.23 \\
\hline $12-24$ & 20 & 38.462 \\
\hline $36-48$ & 08 & 15.38 \\
\hline $48-60$ & 04 & 7.69 \\
\hline$>60$ & 02 & 3.84 \\
\hline Total & $\mathbf{5 2}$ & $\mathbf{1 0 0}$ \\
\hline
\end{tabular}

Table 4. Showing distribution of cases in females according to age group

\begin{tabular}{|l|l|l|}
\hline Age Group (Months) & $\begin{array}{l}\text { No. of } \\
\text { cases }\end{array}$ & Percentage (\%) \\
\hline$<6$ & 1 & 2.272 \\
\hline $6-12$ & 8 & 18.1818 \\
\hline $12-24$ & 19 & 43.1818 \\
\hline $24-34$ & 11 & 25 \\
\hline $36-48$ & 3 & 6.818 \\
\hline $18-60$ & 2 & 4.545 \\
\hline$>60$ & 0 & 0 \\
\hline Total & $\mathbf{4 4}$ & $\mathbf{1 0 0}$ \\
\hline
\end{tabular}

Gradual decline in incidence of febrile seizure is gradual in case of males and marked in case of females as age advances. 
Table 5. Showing height of rectal temperature at the time of admission in febrile seizure patients.

\begin{tabular}{|l|l|l|}
\hline $\begin{array}{l}\text { Temperature } \\
(\mathbf{(} \mathbf{F})\end{array}$ & No. of Cases(M+F) & $\begin{array}{l}\text { Percentage } \\
(\mathbf{\% )}\end{array}$ \\
\hline $99-100$ & $3(2+1)$ & 3.125 \\
\hline $100-101$ & $7(4+3)$ & 7.291 \\
\hline $101-102$ & $28(15+13)$ & 29.166 \\
\hline $102-103$ & $44(22+22)$ & 45.83 \\
\hline $103-104$ & $8(5+3)$ & 8.33 \\
\hline$>104$ & $6(4+2)$ & 6.25 \\
\hline Total & $\mathbf{9 6}$ & $\mathbf{1 0 0}$ \\
\hline
\end{tabular}

From the above observations it is clear that majority of cases (82.28\%) had a temperature in the range of $101-103{ }^{\circ} \mathrm{F}$

Table 6. Showing causes of fever in patients of febrile seizure

\begin{tabular}{|l|l|l|}
\hline Causes & No of Cases (M+F) & Percentage (\%) \\
\hline URTI & $(27+25) 52$ & 54.166 \\
\hline LRTI & $(10+9) 19$ & 19.791 \\
\hline AGE & $(5+3) 8$ & 8.33 \\
\hline URTI + AGE & $(3+3) 6$ & 6.25 \\
\hline Otitis media & $(3+1) 4$ & 4.166 \\
\hline Measles & $(2+1) 3$ & 3.125 \\
\hline Malaria & $(2+2) 4$ & 4.166 \\
\hline $\begin{array}{l}\text { Post } \\
\text { immunization }\end{array}$ & 0 & 0 \\
\hline Total & $\mathbf{9 6}$ & $\mathbf{1 0 0}$ \\
\hline
\end{tabular}

URTI - $\quad$ Upper Respiratory Tract Infection.

LRTI - $\quad$ Lower Respiratory Tract Infection.

AGE - $\quad$ Acute Gastro Enteritis.

Thus majority of cases (84.37\%) had fever secondary to respiratory tract infection (Upper $>$ Lower) There were 4 (4.166\%) cases of malaria with febrile seizures (Two cases were positive for malarial parasites, Plasmodium vivax and two other cases had typical clinical features i.e. intermittent fever with rigors and sweating, splenomegaly; and responded to chloroquine).

Table 7. Showing duration from onset of fever to convulsion in patients of febrile seizure

\begin{tabular}{|l|l|l|}
\hline Duration (hrs) & $\begin{array}{l}\text { No. of Cases } \\
\text { (M+F) }\end{array}$ & $\begin{array}{l}\text { Percentage } \\
\text { (\%) }\end{array}$ \\
\hline Up to 6 & $(16+14) 30$ & 31.25 \\
\hline$>6-12$ & $(16+14) 30$ & 31.25 \\
\hline$>12-24$ & $(15+13) 28$ & 29.16 \\
\hline$>24-36$ & $(4+2) 6$ & 6.25 \\
\hline$>36$ & $(1+1) 02$ & 2.08 \\
\hline Total & $\mathbf{9 6}$ & $\mathbf{1 0 0}$ \\
\hline
\end{tabular}

Majority (91.66\%) of cases had febrile seizure within 24 hours of onset of fever. The two cases having fever $>36$ hours were cases of otitis media where initial fever due to upper respiratory tract infection could not be distinguished from fever due to its complication i.e. otitis media by parents. 
Texila International Journal of Clinical Research

Volume 4, Issue 1, Jun 2017

Table 8. Showing relationship of family history of febrile and non febrile seizure in first degree relatives.

\begin{tabular}{|l|l|l|}
\hline & No. of Cases & Percentage (\%) \\
\hline Febrile Seizure in Relatives & 08 & 8.33 \\
\hline $\begin{array}{l}\text { Non febrile seizure in } \\
\text { relatives }\end{array}$ & 02 & 2.0833 \\
\hline
\end{tabular}

Thus Family history of febrile seizure was observed in $8.33 \%$ of cases whereas family history of nonfebrile was observed in only one case, where mother was on anticonvulsant treatment for 3 years (during the 15 to 18 years of age). In other case Elder brother of age 9 years was suffering from grandmal epilepsy diagnosed at age 7 years now taking anticonvulsants.

Table 9. Showing relationship of parity to occurrence of febrile seizure

\begin{tabular}{|l|l|l|}
\hline Parity & No. of Case & Percentage (\%) \\
\hline $1^{\text {st }}$ & $(23+21) 44$ & 45.833 \\
\hline $2^{\text {nd }}$ & $(13+11) 24$ & 25 \\
\hline $3^{\text {rd }}$ & $(8+7) 15$ & 15.625 \\
\hline $4^{\text {th }}$ & $(4+2) 6$ & 6.25 \\
\hline $5^{\text {th }}$ and above & $(4+3) 7$ & 7.291 \\
\hline Total & $\mathbf{9 6}$ & $\mathbf{1 0 0}$ \\
\hline
\end{tabular}

From the above observations it is seen that first born children are affected more than subsequent sibs.

Table 10. Showing relationship between antenatal, prenatal risk factors and febrile seizures.

\begin{tabular}{|l|l|l|l|}
\hline Sr. No & Risk factors & $\begin{array}{l}\text { No. of } \\
\text { Cases }\end{array}$ & Percentage (\%) \\
\hline 1 & High risk antenatal factors (server PIH) & 1 & 1.0416 \\
\hline 2 & $\begin{array}{l}\text { Difficult birth (prolonged labour and } \\
\text { cesarean delivery) }\end{array}$ & 2 & 2.083 \\
\hline 3 & Birth Asphyxia & 2 & 2.083 \\
\hline 4 & Low birth weight and prematurity & 1 & 1.1 .0416 \\
\hline 5 & $\begin{array}{l}\text { Neonatal seizure (Not attributed to birth } \\
\text { asphyxia, hypocalcemia, } \\
\text { hypomagnesemia) }\end{array}$ & 1 & 1.0416 \\
\hline & Total & $\mathbf{7}$ & $\mathbf{7 . 3 0}$ \\
\hline
\end{tabular}

Thus 7 cases (7.30\%) were having high risk perinatal factors. Out of these 7 cases on patient had developed cerebral palsy (No. 4 - spastic quadriplegia), two (No 3 \& 5 ) were retarded neurodevelopmentally and 4 were normal on follow up. Amongst them two (No. 4 \& 5) developed atypical seizure and rest were simple febrile seizure.

Table 11. Relationship of neurodevelopmental history to febrile convulsion.

\begin{tabular}{|l|l|l|}
\hline & No. of Cases & Percentage (\%) \\
\hline Normal & $90(46+44)$ & 93.75 \\
\hline Abnormal & $6(4+2)$ & 6.25 \\
\hline Total & $\mathbf{9 6}$ & $\mathbf{1 0 0}$ \\
\hline
\end{tabular}

Out of these 6 patients with delayed milestone one was a case of spastic quadriplegia, 2 were retarded neurodevolopmentally due to perinatal risk factors, 2 cases were of primary microcephaly and in one case, cause of neuro developmental retardation could not be determined. 
Table 12. Showing type of convulsion in patients of febrile seizure.

\begin{tabular}{|l|l|l|}
\hline Type & No. of Cases & Percentage (\%) \\
\hline $\begin{array}{l}\text { Generalized tonic } \\
\text { clonic }\end{array}$ & 84 & 87.5 \\
\hline Focal & 8 & 6.66 \\
\hline Tonic & 4 & 4.166 \\
\hline Akinetic & 0 & 0.00 \\
\hline Total & $\mathbf{9 0}$ & $\mathbf{1 0 0}$ \\
\hline
\end{tabular}

Thus majority (87.5\%) of patients had generalized tonic clonic seizures and 8.33 cases had focal seizures.

Table 13. Showing distribution of status epilepticus due to febrile seizure.

\begin{tabular}{|l|l|l|l|l|}
\hline \multirow{2}{*}{ Type } & \multicolumn{3}{l|}{ No. of Cases } & \multirow{2}{*}{ Percentage (\%) } \\
\cline { 2 - 5 } & Male & Female & Total & \\
\hline Generalized & 1 & 1 & 2 & 2.083 \\
\hline Focal & 1 & 1 & 2 & 2.083 \\
\hline Total & $\mathbf{2}$ & $\mathbf{2}$ & $\mathbf{4}$ & $\mathbf{4 . 1 6 6}$ \\
\hline
\end{tabular}

Out of 96 patients, 4 had status epilepticus two each from generalized and focal group (Males 2, Females 2)

Amongst patients with focal febrile status epilepticus, one was a case of spastic quadriplegia and another a case of microcephaly.

Patients with generalized febrile status had no risk factors.

Table 14. Showing duration of convulsion in patients of febrile sezures.

\begin{tabular}{|l|l|l|}
\hline $\begin{array}{l}\text { Duration } \\
\text { (Minutes) }\end{array}$ & $\begin{array}{l}\text { No. of Cases } \\
\text { (M+F) }\end{array}$ & Percentage (\%) \\
\hline$<15$ & $(43+42) 85$ & 88.54 \\
\hline $15-30$ & $(5+2) 7$ & 7.29 \\
\hline$>30$ & $(4+0) 4$ & 4.166 \\
\hline Total & $\mathbf{9 6}$ & $\mathbf{1 0 0}$ \\
\hline
\end{tabular}

From above table it is seen that majority (91.12\%) of cases had brief convulsions lasting less than 15 minutes. Only 4 cases had febrile status epilepticus with duration ranging form 30 minutes for 1 hours.

Table 15. Showing number of episodes of febrile seizures within 24 hours of initial sezures.

\begin{tabular}{|l|l|l|}
\hline No. of episodes & $\begin{array}{l}\text { No. of } \\
\text { Cases(M+F) }\end{array}$ & Percentage (\%) \\
\hline 1 & $89(49+40)$ & 92.70 \\
\hline 2 & $4(2+2)$ & 4.166 \\
\hline 3 & $1(0+1)$ & 1.041 \\
\hline 4 & $1(1+0)$ & 1.041 \\
\hline 5 & $1(0+1)$ & 1.041 \\
\hline Total & $\mathbf{9 6}$ & $\mathbf{1 0 0}$ \\
\hline
\end{tabular}

From above table it is obvious that majority (92.70\%) of patients with febrile seizures had single attacks within 24 hours of initial seizure within 24 hours of initial seizure were seen in $7.30 \%$ cases.

Table 16. Showing duration of cases as typical and atypical febrile seizures.

\begin{tabular}{|l|l|l|l|}
\hline Type & Male & Female & Total \\
\hline Typical & 38 & 32 & $70(72.91 \%)$ \\
\hline Atypical & 14 & 12 & $26(27.08 \%)$ \\
\hline
\end{tabular}


Texila International Journal of Clinical Research

Volume 4, Issue 1, Jun 2017

Thus majority of patients (86.66\%) had typical/simple/benign febrile seizures and 13.32\% of cases had a typically febrile seizure. Also incidence of atypical febrile seizures in males was more than in females (M:F - 1.39:1)

Table 17. Showing nature of atypical febrile seizure

\begin{tabular}{|l|l|}
\hline Factor & $\begin{array}{l}\text { No of } \\
\text { Cases(M+F) }\end{array}$ \\
\hline Duration $>15$ minute & $11(6+5)$ \\
\hline Focal & $8(4+4)$ \\
\hline $\begin{array}{l}>1 \text { Convulsion within } \\
\text { 24hrs. }\end{array}$ & $7(4+3)$ \\
\hline
\end{tabular}

From above it is seen that here is overlap of risk factors for atypical febrile seizures with duration more than 15 minutes being the commonest atypical feature.

Recurrence of febrile seizure: Out of 90 patients, 20 patients were on long term anticonvulsant prophylaxis and had no recurrence during the follow up period. Amongst remaining 70 patients of simple febrile convulsion, 50 patients could be followed up regularly in OPD for a mean period of 12 months. Amongst them 16 patients had recurrence during follow up and 10 cases had more than one recurrences during follow up.

Table 18. Showing number of cases having recurrence according to age group.

\begin{tabular}{|l|l|l|l|}
\hline $\begin{array}{l}\text { Age group } \\
\text { (months) }\end{array}$ & $\begin{array}{l}\text { No. of } \\
\text { Cases }\end{array}$ & $\begin{array}{l}\text { No of Cases With } \\
\text { recurrence }\end{array}$ & Percentage (\%) \\
\hline$<6$ & $(1+0) 1$ & $(1+0) 1$ & 100 \\
\hline $6-12$ & $(5+3) 8$ & $(3+1) 4$ & 50 \\
\hline $12-24$ & $(11+9) 20$ & $(5+3) 8$ & 40 \\
\hline $24-36$ & $(8+2) 10$ & $(1+1) 2$ & 20 \\
\hline $36-48$ & $(4+2) 6$ & $(1+0) 1$ & 16.66 \\
\hline $48-60$ & $(3+1) 4$ & 0 & 0 \\
\hline$>60$ & $(1+0) 1$ & 0 & 0 \\
\hline Total & $\mathbf{5 0}$ & $\mathbf{1 6}$ & $\mathbf{3 2}$ \\
\hline
\end{tabular}

Thus it is seen from the table 18 that young age on set of febrile seizure was most significant risk factor for recurrence of febrile seizure. It is also seen that all cases (100\%) with onset at less than 6 months of age had recurrence whereas half children (50\%) with onset during 6-12 months of life had at least one recurrence while $40 \%$ recurrence rat of febrile sezure was seen with onset during the second year of life and $10 \%$ for onset during third year of life.

Out of 16 cases with recurrence family history of febrile Seizure was observed in 2 (12.5\%) cases.

Complex/ atypical febrile seizure recurrence: Only one case out of 50 cases of simple febrile seizure had atypical febrile seizure at the time of first recurrence (2 seizure episodes within 24 hours). This patient was not started on anticonvulsant prophylaxis because the patient had crossed the sensitivity period for recurrence of febrile seizure (age of patient was 30 months).

No other case had atypical febrile seizure at latter recurrences.

Nonfebrile seizure recurrence: No case of simple febrile seizure developed recurrent nonfebrile sezures / epilepsy during follow up period.

Discussion: This study was undertaken to evaluate clinical profile of febrile cases admitted to our hospital. The period of study was from Aug 2014 to Jan 2016.

The total number of patients admitted during this period were 2200 out of which 96 cases were of febrile seizures thus accounting of $4.36 \%$ of hospital admissions.

Occurrence of seizure is a very frightening experience to parents thus generating anxiety and apprehension in their minds and at times in the minds of primary care physicians too. Therefore majority of such cases are brought for hospital management. 
6 month to 3 years of age comprised of $79.16 \%$ of cases. The percentage of seizure in the same age group in different studies is

\begin{tabular}{|c|c|}
\hline Bhandari $^{20}$ & $76.5 \%$ \\
\hline Wolf S.M ${ }^{44}$ & $89 \%$ \\
\hline Sehgal $H^{18}$ & $81.4 \%$ \\
\hline Helen \& Parry ${ }^{23}$ & $82 \%$ \\
\hline Anandam ${ }^{12}$ & $90 \%$ \\
\hline Wadjawa et al $^{29}$ & $75 \%$ \\
\hline Deng C.t. et al ${ }^{72}$ & $92.9 \%$ \\
\hline
\end{tabular}

The number of patients having onset of febrile seizure before 6 months of age were $3.125 \%$ which is not a variance with the findings of Eileen Ouellette, Nelson K.B and J.H. Ellenberg.

Also the percentage of febrile seizure after 5 years is $2.83 \%$ which is similar to that reported by Eileen Ouellette ${ }^{1}$, V.Puri ${ }^{15}$, Franzten et al.

The fall of incidence of febrile seizure occurs after 2 years of age; it is a sharp in females where as gradual in males. This might have due to rapid rate of myelination and cerebral maturation as postulated by Taylor ${ }^{1,15}$.

The peak age of predilection for febrile seizure in our study 16 to20 months was as Hertz D.G. ${ }^{13}$ reported in to be 18 to 20 months.

The peak age of predilection is a true factor for age and not an artifact of the susceptibility to infectious diseases. The relative lack of myelination in the immature brain, its changing chemical composition, changes in water-electrolyted balance, increased oxygen consumption, diminished dendritic connections and electrophysiological differences from the adult brain have all been implicated as possible reasons for the remarkable correlation between febrile convulsion and restricted age group ${ }^{1}$.

Male to female ratio observed in this study was 1.18:1 which is similar to that reported by Bhandari ${ }^{20}$, Rutter \& Smales ${ }^{11}$, Helen Parry ${ }^{23}$, H. Sehgal \& Kiran Bala ${ }^{18}$, Millichap ${ }^{21}$, Lennox Buchthal ${ }^{27}$, Kundsen ${ }^{65}$, Peggy Bethun ${ }^{73}$.

However, Ounsted ${ }^{32}$ made astute observation that the excess of males was due to excess of boys from one sex sibship. He gave male to female ratio in mixed sibship as 1.05: Where in one sex sibship was 1.6:1.

So far there has been no satisfactory explanation of this curious gender difference but it is postulated that the rapid rate of cerebral maturation and myelination in females is responsible for observed male preponderance.

Thus in general, in almost all series febrile seizure have Occurred more frequently in males with male to ratio ranging from 1.1: to $4: 1^{1,15,21}$

In present study, $74.94 \%$ cases had temperature in range of 101 to $103^{0} \mathrm{f} \& 3.125-99$ to $100^{\circ} \mathrm{F}$ and $6.25 \%>104^{0} \mathrm{f}$

N.R Bhandari ${ }^{20}$ Found $68.4 \%$ with temperature $101-104{ }^{0} \mathrm{f}$ and $27.7 \%$ had more than $104^{0} \mathrm{f}$ Hirtz D.G ${ }^{13}$ found $75 \%$ Cases with temperature more than $102^{0} \mathrm{f}$

H. Sehagal \& Kiran Bala ${ }^{18}$ had $9.5 \%>100^{0} \mathrm{f}$, 43.5> $100-103^{0} \mathrm{f}, 47 \%>103-106^{0} \mathrm{f}$. The mean temperature was $103^{0} \mathrm{f}$.

Eileen Ouellette ${ }^{1}$, V. Puri ${ }^{15}$ also states that rectal temperature is usually $39^{0} \mathrm{C}\left(102^{0} \mathrm{f}\right)$ in majority of cases.

In our study $91.66 \%$ of cases had febrile seizure within 24 hrs. of fever.

H. Sehegal \& Kiran Bala ${ }^{18}$ Observed 84\% cases within 24 hrs of fever.

Livingstone ${ }^{7}$ observed that simple febrile seizure begins from 2-6 hrs. After onset of fever and in no case found fever-convulsion duration more than $24 \mathrm{hrs}$.

Eileen Ouellette ${ }^{1}$ gives fever - convulsion duration in the range of few minutes to 2 days.

V. Puri ${ }^{15}$ also states that duration of fever prior to seizure is almost always less than 24 hrs and most seizures occur in the first few hours after the fever has begun. 
Texila International Journal of Clinical Research

Volume 4, Issue 1, Jun 2017

In our series, 2.08\% of cases had fever convulsion duration more than 36 hours in cases of otitis media where initial fever due to URTI could not be separated from fever due to its complications i.e. otitis media.

Deborah G. Hirtz also observed that in few cases, where otitis media supervenes during URTI, fever-convulsion duration may be greater than 24 hours.

Majority of cases (73.95\%) had fever due to respiratory tract infection. Acute gastroenteritis, A.G.E with URTI and malaria accounted for $6.25 \%$ and $4.166 \%$ respectively. Otitis media for $4.166 \%$ and measles accounting for $3.125 \%$ of cases.

N.R. Bhandari ${ }^{20}$ had $94.5 \%$ cases due to respiratory tract infection (63\%-URTI, 31.5\% LRTI)

Simpson \& George ${ }^{40}$ had 70\% - URTI, 20\%-LRTI,5\% UTI and mumps and remaining 5\% infected tarsal plate.

H. Sehagal \& Kiran Bala ${ }^{18}$ in their study of 150 cases found URTI - 66.6\% LRTI $10.6 \%$, Otitis media $-11.3 \%$ and gastroenteritis $-11.5 \%$.

Ramkrishanan ${ }^{83}$ et al slos had 70\% patients with viral fever, $5 \%$ with +ve Mantaux test and -ve X-ray chest, $15 \%$ with +ve Mantaux and x ray showing primary complex, $8 \%$ pneumonia, $2 \%$ otitis media.

Wadhwa et $\mathrm{al}^{29}$ found $69.4 \%$ cases with respiratory tract infection.

Harker $^{41}$ gave the incidence of febrile seizure within 28 days following immunization as 0.09/1000 after triple vaccine and 0.6/1000 after measles immunization.

Stive Kohl ${ }^{9}$ gives high rate of febrile seizure in exanthema subitum as high as 5.35\%.

In Africa, the causative infections are different from those in western countries. Patel \& Familusi et $\mathrm{al}^{80}$ Found malaria as a frequent cause as is septicaemia. In a study by Ejeheri et $\mathrm{al}^{81}$, they found malaria as one of the major cause of fever which accounted for $32.7 \%$ of cases followed by bronchopneumonia - $16.8 \%$ measles - $15.4 \%$ Otitis media $-13.4 \%$ and tonsillitis $-10.5 \%$.

In the present study, we did not find a single case of febrile seizure either following immunization or due to roseola infantum. This may be due to small sample size and lack of facilities for virological studies.

Fever due to malaria was an important cause of febrile seizure thus depicting its significance in endemic areas, a fact not highlighted by studies in many western countries.

Family history of febrile and non febrile seizure in first degree relatives was seen in $10.41 \%$ and $2.08 \%$ cases respectively.

The positive family history of febrile seizure in different studies is

\begin{tabular}{|l|l|}
\hline Ramkrishnan et al $^{83}$ & $5.8 \%$ \\
\hline Kundse $^{28}$ & $5.83 \%$ \\
\hline Wadhwa et al $^{29}$ & $13.9 \%$ \\
\hline
\end{tabular}

The positive family history of nonfebrile seizures in different studies is

\begin{tabular}{|l|l|}
\hline Bhandari $^{20}$ & $10 \%$ \\
\hline Sehagal \& Kiran Bala $^{12}$ & $17 \%$ \\
\hline Knudsen $^{28}$ & $24.8 \%$ \\
\hline Ramkrishnan et al $^{83}$ & $15.8 \%$ \\
\hline Wadhwa et al & $20 \%$ \\
\hline Deng C.T. et al & $26.5 \%$ \\
\hline Peggy Bethune et al & 73 \\
\hline A van Esch $^{78}$ & $16.2 \%$ \\
\hline
\end{tabular}

The low incidence observed in our study may be due to small sample size, under reporting, ignorance, lack of education and inadequate health facilities.

Franzten et al ${ }^{82}$ says that it also depends on how frank the population attitudes are with respect to convulsion, In any case, more positive family histories are obtained in well cultured highly educated parents. In our study first born children were affected more commonly ${ }^{45}$. 
83.3\% than subsequent sibs, similar to finding of Bhandari N.R ${ }^{20}$ Sehgal \& Kiran Bala ${ }^{18}$ ,however Peggy Bethune ${ }^{73}$ did not find any relationship between febrile seizure and parity.

However due to adoption of small family norms in recent times, it is very likely that first born children will constitute largest group amongst affected children. High risk perinatal factors were observed in $7.30 \%$ of cases.

Wallace ${ }^{24}$ in her study found that children who later convulse are significantly more likely than their sibs to have weight below $10^{\text {th }}$ centile. If male, they are more likely to have fetal distress during labour. The incidence of LSCS compared with vaginal delivery is higher. She found that $61 \%$ children with febrile seizure had at least one risk factor which was commoner among convulsers than their siblings.

Millichap ${ }^{21}$ stated that prenatal difficulties have been present from 3 to $61 \%$ of patients with febrile convulsion in various studies.

However Nelson K.B. et al in their large American prospective cohort study did not find complication of labour as an important risk factor but they found maternal illness. Prenatal maternal smoking and neonatal insults too be associated with modest increase in risk of febrile seizure. Premature birth was found to be more common in cases than in controls by farsgren et al Cassno P.A et al also found that prenatal maternal alcohol intake and smoking increases risk for febrile seizure. ${ }^{84}$

Peggy Bethune ${ }^{73}$ found delayed neonatal discharge (more than 28 days due to difficulties in neonatal period) in $8 \%$ cases versus $1.7 \%$ in controls, birth weight less than $1.5 \mathrm{~kg}$ in $4 \%$ versus $0 \%$ in controls. We also observed similar findings.

It was abnormal in $6.25 \%$ of cases in our study, but Eileen Ouellette, Millichap, Wallace, Nelson K.B., Peggy Bethune observed previous neurological abnormality in a large number of childrens with febrile seizure (range 9.3-23\%)

However, meaningful comparison between different studies have not been possible because some workers excluded children with previous neurological abnormalities while defining febrile seizure, e.g. Livigston ${ }^{1}$, the joint Working Group of British Physicians and Pediatricians.

Percentage of different seizure was

\begin{tabular}{|l|l|}
\hline Generalized tonic clonic & $87.5 \%$ \\
\hline Tonic & $4.166 \%$ \\
\hline Focal & $8.33 \%$ \\
\hline
\end{tabular}

Similar findings observed by N.R. Bhandari ${ }^{20}$, wolf S.M, et $\mathrm{al}^{44}$, Sehgal \& Kiran Bala ${ }^{18}$, K. Ramkrishnan83, Nelson K.B. ${ }^{31}$ however, Wallace \& Zelly ${ }^{24}$ had higher number of cases with focal seizures (generalized $-66.6 \%$, focal $-33.3 \%$ )

We observed duration less than 15 minutes in $88.5 \%$ of cases, 15 to 30 minutes- $7.29 \%$ \& more than 30 minutes $-4.166 \%$.

Duration of seizure less than 15 minute in different studies was

\begin{tabular}{|c|c|}
\hline Knudsen $^{28}$ & $93.77 \%$ \\
\hline Nelson K.B ${ }^{31}$ & $92.4 \%$ \\
\hline Rutter \& Smales ${ }^{11}$ & $85.0 \%$ \\
\hline Fishman $^{26}$ & $92.8 \%$ \\
\hline
\end{tabular}

Majority of cases had duration less than 15 minutes in different studies including ours.

We observed $92.70 \%$ with single seizure and $7.30 \%$ with multiple seizures (more than one within 24 hours of initial seizure) Percentage of multiple seizures in different studies is

\begin{tabular}{|l|l|}
\hline Millichap $^{21}$ & $33.3 \%$ \\
\hline Bhandari N.R $^{20}$ & $29 \%$ \\
\hline Sehagal \& kiran Bala & 18 \\
\hline Nelson K.B & $34.6 \%$ \\
\hline
\end{tabular}


Texila International Journal of Clinical Research

Volume 4, Issue 1, Jun 2017

\begin{tabular}{|l|l|}
\hline Fishman $^{26}$ & $16 \%$
\end{tabular}

We observed lower percentage of cases with multiple seizures, which may be due to round the clock antipyretic measure adopted for admitted patients.

Simple / Typical / Benign febrile seizures were seen in $72.91 \%$ of cases and Atypical/Complex in $27.08 \%$ cases.

The percentage of atypical febrile seizure in different studies were as follows:

\begin{tabular}{|l|l|}
\hline Helen \& Parry $^{23}$ & $33 \%$ \\
\hline Knudse $^{28}$ & $16.26 \%$ \\
\hline Fishman & 26 \\
\hline Nelson K.B & $4 \%$ \\
\hline Deng $^{12}$ & $18.14 \%$ \\
\hline Wadhwa $^{29}$ & $33.3 \%$ \\
\hline Peggy Bethune $^{73}$ & $34.02 \%$ \\
\hline
\end{tabular}

Thus percentage of atypical febrile seizure in different studies varies from 4 to $33.3 \%$ and on an average $15 \%$ cases have atypical seizures.

Amongst patients with no previous neurological abnormality (90 cases) $22.22 \%$ had atypical seizure whereas in those who were abnormal (6 cases,) 50\% had atypical seizures. Also, we observed that the incidence of atypical febrile seizure in Children having previous.

Nerurological deficit is $50 \%$. But in a study by Ellenberg $\mathrm{J} . \mathrm{H}^{19}, 22.10 \%$ of atypical febrile occurred in children with previous neurological abnormality.

Millichap ${ }^{21}$,Eillen oullette ${ }^{1}$, Wallace Livingston ${ }^{7}$ also observed that a typical seizures occur more commonly in children with previous neorulogical abnormality. Eileen Ouellette considered atypical seizure as epileptic seizures, precipitated by fever and to carry a graver prognosis and termed them as seizure with fever. 4.166 of cases of febrile status epilepticus (2.083\% generalized, $2.083 \%$ focal) with equal frequency in males and females $(2.083 \%$ each) Patients with generalized status had no risk factors whereas those with focal status had previous neurological abnormalities.

The male to female ratio of atypical febrile seizure and febrile status in our study was 1:1.18 showing female preponderance.

H. Sehgal \& Kiran Bala ${ }^{18}$, wolf S.M. et $\mathrm{al}^{44}$ had $3 \%$ and $2.15 \%$ children with febrile status epilepticus respectively.

Eileen Ouellette ${ }^{1}$,Lennox- Buchthal ${ }^{27}$ noted that though febrile convulsions occurs more frequently in male than females, complex febrile seizures, febrile status epilepticus and their sequelae are more common in females.

Nelson K.B. et $\mathrm{al}^{31}$ found that children with onset seizure before 1 year of age and previous neurological abnormality were more likely to have several febrile fits.

Factors indentified by Wallace 24 Predisposing to servere initial Convulsions are young age, Pre-exiting neurological disorders, birth abnormalities and family history of convulsive disorders.

Our findings are similar to above observations.

Malnutrition - 33.33\% (Mild-23.33\%, Moderate-10\%)

Anemia $-41.66 \%$

Cervical lymphadenopathy $-10.41 \%$ (2.08\%- Mantoux Positive and 1.04\% x-ray chest showing calcified lymph node)

These findings correspond with general prevalence of malnutrition, anemia and tuberculosis infection in our population, especially in rural areas.

One of our patients was initially diagnosed as atypical febrile seizure but same case was readmitted after 2 weeks asymptotic period for focal seizure, low grade fever and this time he had vomiting also. Patient was reinvestigated (including CT scan and proved to be a case of neurotuberculosis and was excluded from the study) 
Complications: Only immediate complication were studied. No death occured in the cases studied in this series. No patient developed aspiration pneumonia secondary to seizure. Hemiplegia or associated motor deficit was not observed during or soon after febrile convulsion in any case. Also patient who had multiple convulsions during one febrile episode were normal in between the attacks.

Menekes ${ }^{1}$ give the fatality rate to be $0.08 \%$ with febrile seizure.

Ellenberg J.H ${ }^{19}$ also did not observe any death due to febrile seizure in their study.

V.Puri ${ }^{15}$ also noted that in the absence of pre-existing neurological disturbance, there does not appear to be any significant mortality associated with febrile seizure.

Freeman ${ }^{47}$ also stated that there is no evidence that febrile seizure increases risk of death.

Amongst remaining 70 Patients, 50 could be followed up regularly for a average period of 12 months. Out of them 32\% (16 cases) had at least one recurrence during the short follow up period.

\section{The recurrence rate observed was}

\begin{tabular}{|l|l|l|}
\hline Onset $<6$ months of age & - & $100 \%(1$ case $)$ \\
\hline $6-12$ months & & $50 \%$ \\
\hline $12-24$ months & $40 \%$ \\
\hline $24-36$ months & $10 \%$ \\
\hline
\end{tabular}

Thus young at onset of seizure was a very significant risk factor for recurrence, as mentioned in many other studies the percentage of recurrent febrile seizure in different studies is

\begin{tabular}{|c|c|}
\hline Thilothammal $^{14}$ & $-\quad 40 \%$ \\
\hline Sehgal \& Kiran Bala ${ }^{18}$ & $46 \%$ \\
\hline Nelson K.B. et al ${ }^{19}$ & $32 \%$ \\
\hline Wallace $^{24}$ & $47 \%$ \\
\hline Lennox-Buchthal $^{27}$ & $41.8 \%$ \\
\hline Ramdrishnan ${ }^{83}$ & $17 \%$ \\
\hline Knudsen $^{28}$ & $22.40 \%$ \\
\hline Berg A.T.et $\mathrm{al}^{63}$ & $34.3 \%$ \\
\hline A Van Esch ${ }^{78}$ & $31 \%$ \\
\hline
\end{tabular}

It is stated that $50 \%$ recurrences occur within 7 months of initial seizure, $70 \%$ within 1 year and $88 \%$ within 24 months of initial seizure19. Inspite of short follow up period, we also observed $32 \%$ recurrence rate in our study.

Family history of febrile seizures was present in $12.5 \%$ (2 cases). Nelson K.B. et al19, Sehgal \& Kiran Bala18, Lennox-Bechthal27 Knudsen28, R.Anandam14, Berg A.T63, A van Esch78 observed similar findings,

No case developed epilepsy (recurrent non febrile seizures) during the short follow up period of our study. This could be explained by small sample size, short follow up period and rarity of positive family history of epilepsy in our study.

\section{References}

[1]. Anne T. Berg, Comment on - diazepam to prevent febrile seizure, N.E.J.M. 1993; 329(27):2033.

[2]. A van Esch et al, Family history and recurrence of febrile seizure, Arch Dis. Child 1994; 70:39599.

[3]. A Hopkins et al, Febrile convulsions, B.M.J. 1991; 303:634-36.

[4]. Antret E. et al, Double blind trial of diazepam versus placebo for prevention of recurrent febrile seizure., J. Ped. 1990; 117(3); 490-94.

[5]. A Van Esch, Antipyretic efficacy of ibuprofen and acetaminophen in children with febrile seizure., Arch. Ped.Adol.Med.,1995;146(6):632-37.

[6]. Aicardi J., Chevrie J.J., Convulsive status eoilepticus in infants and children Epilepsia, 1970; 11:87797. 
Texila International Journal of Clinical Research

Volume 4, Issue 1, Jun 2017

[7]. Anandam R., Febrile seizures, Indian Pediatrics, 1986; 23:899-903.

[8]. Allen W.H., The natural history of febrile seizure cited in "Febrile Seizure", Edited by K.B., Nelson \& J.H.Ellenberg, Febrile seizures, Ravan Press,1981:31-39.

[9]. Ajay Kalra et al, Rectal diazepam in convulsion disorder, Indian Pediatrics, 1992; 29:975-78.

[10]. Baraitser M., Relevance of family history of febrile seizure, Arch. Dis. Child, 1983; 58:405-8.

[11]. Brockebank J.J. et al, Influenza A infections in children, Lancet, 1972; 2:497-99.

[12]. Berga A. T. et al, What we have learnt from febrile seizure? Ped. Ann. 1992; 21(6); 355-56, 35961, 54 Kundsen F. U ; 355-56,359-61.

[13]. Camfield P. et al, What type of epilepsy are preceded by febrile seizure? Dev. Med. Child, Neurol., 1994; 36(10):887-92.

[14]. Chhaparwal et al m mg++ level in serium and C.S.F. in febrile seizures I.J.P. 1971; 38:241-45.

[15]. Cassano P.A. et al, Risk of febrile seizure in childrenin relation to prenatal matemal smoking and alcohol intake.

[16]. Calderon - Gonzaler R., Bol. Med. Hosp. Infant Mex, 1990 Jan 47(1)7-13.

[17]. Charles A. Fischbein, Peter Camfield, Comment on diazepam to prevent febrile seizure. N.E.J.M., 1993; 329(27):2033-34.

[18]. Cary W, Febrile convulsions in infants and children, Med. J. Australiya, 1956’43:254-56

[19]. Consensus Statement, National Institute of Health - Febrile seizure, Ped. 1980;66(6):1009-12.

[20]. Davies K. G. et al, Relationship of hippocampal scelerosis to epilepsy and complex febrile sezure in temporal labectomy patients, Epilepsys Res. 1996;24(2):199-26.

[21]. Deng. C.T., Zulkifli H. I., Azizi B.H, Febrile seizures in Malaysian children- epidemiology and clinical features med. J. Malaysia,1994;49(4):341-7.

[22]. Dannish Medical research 2002.

[23]. Downham M.A et al, Diagnosis and Clinical significance of oarainfluenze virus infection in children, Arch Dis. Child, 1974;49:8-12.

[24]. David A. Bergman et al, The practice parameter- neurodiagnostic evaluation of child with

[25]. Eillen M. Outllette, The child who convulses with fever, P.C.N.A 1974;21:467

[26]. E.M.Brett Epilepsy and Convulsions

[27]. Ejeheri N.A. et al, Etiology of febrile seizures, Annals of Tropical Medicine, 1994:14(3)211-14.

[28]. First simple febrile seizure, Pediatrics (American) 1996;97(5):769-72.

[29]. Freeman J.M, The best medicine for febrile sezure, N.J.M 1992:327:1161-63.

[30]. Franzten F. et al, A gentic study of febrile convulsion, Neurology, 1970:20:909-17.

[31]. Freeman j .m what we have learnt from febrile seizure ? ped.ann, 1992:21(6); 355-56, 35961.65.knudsen f.u 355-56, 359-61.

[32]. Farewell J.R. et al, Phenobarbitone for fevbrile seizure- effect on intelligence and seizure recurrence N.E.J.M. 1990; 322(6):364-9.

[33]. Green s. M. et al, Can seizures to be the sole manifestation in febrile children, Pediatrics, 1993; 92(4):527-34.

[34]. Haddow M. Keith, Convulsion disorder in children, $1^{\text {st }}$ ed. 1970:37-49

[35]. Hertz D.G. et al, Febrile seizure, P.C.N.A. 1989; 2:375-82.

[36]. Harker P., Primary immunization and febrile convulsion B.M.J. 1977;2:480-85.

[37]. Harvey A.S et al, Febrile seizures and hippocampal sclerosis - frequent and related finding in temporal lobe epilepsy of childhood, Ped. Neurology, 1995:12(3):201-6.

[38]. In: Pediatric Neurology, Edinburgh, Churchill Liningstone, 1997:283, 342- 52

[39]. John H. Menkes, Febrile Convulsions In: Texbook of Child Neurology

[40]. Knudsen F.U, Recurrence Risk After first febrile seizure and effect of short term diazepam prophylaxis, Arch Dis. Child, 1985; 60:1045-49.

[41]. Knudsen F.U., Febrile seizure- Treatment and outcome, Brain Develop., 1996; 18 (6;438-49.

[42]. K Ramkrishanan et al, Causes of fever in febrile convulsion I.J.P. 1982;49;367-369

[43]. Kuturee M. et al, Febrile seizure: Is EEG useful predicator of recurrence, Clinical Ped. (Phila), 1997:136(1):31-36.'

[44]. Kuks J. B., Hippocampal sclerosis in epilepsy and childhood febrile seizures Lancet, 1993;342((8884):1391-94. 
[45]. Knudsen F.U., Fectal administration of diazepam in solution in the acute treatment of convulsion in infants and children, Arch Dis, Child, 1979;54:855-57.

[46]. Livingstone S. et al, Febrile convulsion - A clinical study with special reference to heredity and prognosis, J. Pediatrics, 1947; 31:509-12.

[47]. Lindsay J.M., Genetics and epilepsy, A model from critical pathological analysis. Epilepsia, $1971 ; 12: 47-52$.

[48]. Lennox W. G. Epilepsy \& Related Disorders, Ed. Little, Brown, Boston, 1960:1168-82.

[49]. Leonard Banco, Daniel Veltri, Ability of mothers to subjectively assess the degree of fever in their children A.J.D.C., 1984; 138:976-78.

[50]. Nelson K.B. \& Ellenberg J.H. Predicators of epilepsy in children who have experienced febril seizures, N.E.J.M. 1976; 259:1029-33.

[51]. Ounsted C, Some aspect of seizure disorders, Edited by Hall D. and Gairdner D, Recent advances in pediatrics, Churchill, London 1970'102-8.

[52]. P. Singhi K.M. Shriniwas, Journal of pediatrics 2001 38:733-740.

[53]. Peggy Bethune et al, Which child will have febrile seizure, A.J.D.C. 1993;147:935-39.

[54]. P.D. Singhi, K. Jayshree, Febrile seizures - an update, Indian Pediatrics,

[55]. Philadelphia, Lea\& Febiger, 1985: 608,654-56

[56]. Peterman M.G., Febrile convulsion, J. Pediatrics, 1952:41:536-40

[57]. Puri V, Febrile seizure, Indian pediatrics, 1991;28:309-16.

[58]. Wadhwa N. et al, An epidemiological study of febrile seizures with special reference to family history and HLA linkage.

[59]. Rosman N.P, Controlled trial of diazepam during febrile illness to prevent recurrence of febrile seizures, N.E.J.M. 1993:329(2):79-84.

[60]. Rutter \& Smale, Role of routine investigation in children with first febrile convulsion, Arch Dis. Child. 1977;52:188-91.

[61]. Rosman N.P. Coltant, A controlled trial of diazepam administrated during febrile illness to prevent recurrence, NENGIJ Med. 1993-79 85.

[62]. Robert H.A. Haslam, Febrile seizures, In: Richard E. Behrman et al eds, Nelson Textbook of Pediatrics, Prism Books Pvt.1996:1691.

[63]. Robert - Bauma nn MD, e-Medicine, Febrile seizure-2001, Depth of Neurology, University of Kentucky.

[64]. Rober J. Bauman et al, Technical Report sommery - The neurodignostic evaluation of a child with first simple febrile seizure, Pediatrics (American)1996;97:773-75.

[65]. Simpson \& georage, C.S.F. acid base status and lactate and pyruvate concentration after short ( $<30$ minute) first febrile seizure, Arch Dis. Child, 1977;52:836-43.

[66]. Spirer et al, Hyoerglycemia and convulsion in children, Arch. Dis. Child, 1974;49:811-13.

[67]. Stephen Ryan, Rudolph Texbook of Pediatrics, McGrawhill 2002;2270-71.

[68]. Thilothammal et al, Risk factors for recurrence of febrile seizure, I.J.P.1977;38:169-73.

[69]. Tusuboi T, Genetic aspect of febrile convulsion, Human Genetics, 1977; 38:169-73. 1995; 32:564-72.

[70]. Thomas W. Farmer, Febrile seizure Pediatric Neurology, $3^{\text {rd }}$ ed, 1983; 132-34.

[71]. Uhari M. et al, Effect of acetaminophen an flow dose diazepam in prevention of recurrent febrile seizure. J.Ped. 1995; 126(6):991-95.

[72]. Van staijvenberg M. et al, Controlled trials of ibuproten syp. During fever to prevent recurrence Peadritics 1998 102(s).

[73]. Veena Kalra, Management of febrile convulsion, I.J.P, 1985; 52:177-78.

[74]. Wegman M.E., Factors influencing relation between convulsion and hyperthermia, J. Pediatrics, 1970;14:190-202.

[75]. Wallace S.J. Zeally H, Neurological, Electroencephalographic and virological findings in febrile convulsion., Arch Dis. Child,1970;45:611-23.

[76]. Wolf S.M. et al, A controlled prospective study, Pediatrics, 1977; 59(3):59(3):378-85.

[77]. Wallace s. Simith J.A., Successful prophylaxis against febrile convulsion with valproate B.M.J. 1980;28:253-56. 